NBER WORKING PAPER SERIES

NEW EVIDENCE ON REAL WAGE CYCLICALITY
WITHIN EMPLOYER-EMPLOYEE MATCHES

\author{
Donggyun Shin \\ Gary Solon \\ Working Paper 12262 \\ http://www.nber.org/papers/w12262
}
NATIONAL BUREAU OF ECONOMIC RESEARCH
1050 Massachusetts Avenue
Cambridge, MA 02138
May 2006

The authors grateful acknowledge helpful comments from Charlie Brown, Paul Devereux, and Eric Swanson. The views expressed herein are those of the author(s) and do not necessarily reflect the views of the National Bureau of Economic Research.

(C)2006 by Donggyun Shin and Gary Solon. All rights reserved. Short sections of text, not to exceed two paragraphs, may be quoted without explicit permission provided that full credit, including $\odot$ notice, is given to the source. 
New Evidence on Real Wage Cyclicality within Employer-Employee Matches

Donggyun Shin and Gary Solon

NBER Working Paper No. 12262

May 2006

JEL No. E3, J3

\begin{abstract}
In the most thorough study to date on wage cyclicality among job stayers, Devereux's (2001) analysis of men in the Panel Study of Income Dynamics produced two puzzling findings: (1) the real wages of salaried workers are noncyclical, and (2) wage cyclicality among hourly workers differs between two alternative wage measures. We examine these puzzles with additional evidence from other sources. Devereux's finding of noncyclical real wages among salaried job stayers is not replicated in the National Longitudinal Survey of Youth data. The NLSY data, however, do corroborate his finding of a discrepancy for hourly workers between the cyclicality of the two alternative wage measures. Evidence from the PSID Validation Study contradicts Devereux's conjecture that the discrepancy might be due to a procyclical bias from measurement error in average hourly earnings. Evidence from the Bureau of Labor Statistics establishment survey supports his hypothesis that overtime work accounts for part (but not all) of the discrepancy. We conclude that job stayers' real average hourly earnings are substantially procyclical and that an important portion of that procyclicality probably is due to compensation beyond base wages.

Donggyun Shin

College of Economics and Finance

Hanyang University

Seongdong-Gu, Haengdang-Dong 17

Seoul, 133-791

SOUTH KOREA

dgshin@ hanyang.ac.kr
\end{abstract}

Gary Solon

Department of Economics

University of Michigan

Ann Arbor, MI 48109

and NBER

gsolon@umich.edu 


\section{New Evidence on Real Wage Cyclicality within Employer-Employee Matches}

Until a few years ago, macroeconomists firmly believed that real wages in the United States (and elsewhere) are nearly noncyclical, showing little systematic variation between recessions and expansions. This conventional wisdom was based on a long history of aggregate time series evidence. The stylized fact of weak wage cyclicality spawned numerous macroeconomic theories designed to explain how large cyclical swings in employment could be accompanied by relatively little wage variation. These theories included efficiency wage models, implicit contract models in which employers provide real wage insurance to workers, and insider-outsider models. ${ }^{1}$

More recently, a series of studies based on longitudinal microdata has demonstrated that real wages in the United States actually are quite procyclical, rising more rapidly in expansions than in recessions. ${ }^{2}$ As shown in Solon, Barsky, and Parker (1994), the true procyclicality of real wages is obscured in aggregate time series data because of a composition bias: the aggregate statistics are constructed in a way that gives more weight to low-skill workers during expansions than during recessions. In contrast, studies based on longitudinal microdata have been able to avoid composition bias by following the same workers over time.

Some of these studies - such as Bils (1985) and Shin (1994) - have noted that the wage procyclicality revealed by longitudinal data is especially pronounced among workers

\footnotetext{
${ }^{1}$ Blanchard and Fischer (1989:19), for example, declared, "The correlation between changes in real wages and changes in output or employment is usually slightly positive but often statistically insignificant," and then they devoted much of their Chapters 7-9 to discussing theories designed to account for weak wage cyclicality. See Solon and Barsky (1989) for a detailed summary of the time series evidence and Solon, Barsky, and Parker (1994) for a discussion of the ways in which that evidence influenced macroeconomic theory.

2 Much of this literature is reviewed in Section IV of Solon, Barsky, and Parker (1992).
} 
who change employers. It is not surprising that workers who change employers in an expansion tend to enjoy wage gains, while workers displaced from their jobs in a recession tend to suffer wage losses. But several studies - including Bowlus (1993), Solon, Barsky, and Parker (1994), Shin (1994), and Shin and Shin (2002) - also have found substantial wage procyclicality among workers who stay with the same employer.

In the most thorough research to date on wage cyclicality among job stayers, Devereux (2001) studied male stayers in the Panel Study of Income Dynamics (PSID). ${ }^{3}$ The special features of Devereux's analysis were: (1) by focusing on workers who stayed with the same employer and held only one job, he obtained cleaner measures of wage change within employer-employee matches; (2) he disaggregated his analysis between salaried workers and workers paid by the hour; and (3) he compared two different wage measures. Most other longitudinal studies of wage cyclicality had used the ratio of annual earnings to annual hours of work, henceforth "average hourly earnings." Devereux also used a directly reported hourly wage or per-period salary. While replicating many of the results in earlier research, Devereux's analysis also generated two puzzling findings. First, he found very little wage cyclicality among salaried workers, indicating virtually no tendency for better raises in "good times." Second, for hourly workers, he got discrepant results between the two wage measures. Like other researchers, he estimated substantial procyclicality in average hourly earnings, but he found almost no cyclicality in the directly reported hourly wage.

In this article, we further explore these puzzles by complementing the evidence from the PSID with additional data from the National Longitudinal Survey of Youth (NLSY), the PSID Validation Study, and the Bureau of Labor Statistics establishment survey. We investigate which of Devereux's PSID results are replicated in the NLSY, and we use the

\footnotetext{
3 See Solon, Barsky, and Parker (1994) for evidence on the cyclicality of women's real wages.
} 
other two data sources to investigate the extent to which Devereux's findings might be explained by measurement error or overtime pay.

\section{Econometric Methods and Data}

Following Bils (1985), most longitudinal studies of real wage cyclicality have estimated the model

$$
\Delta \ln w_{i t}=\beta \Delta U_{t}+\delta t+\alpha^{\prime} X_{i t}+\varepsilon_{i t}
$$

where $\Delta \ln w_{i t}$ is the difference between the natural logarithm of worker $i$ 's real wage rate in year $t$ and his log real wage in year $t-1$. The explanatory variable of main interest is $\Delta U_{t}$, the year-to-year change in the annual national unemployment rate. Its coefficient $\beta$ is negative, zero, or positive as the real wage is procyclical, noncyclical, or countercyclical. The regression also includes a linear time trend and a vector $X_{i t}$ containing an intercept and measures of the individual's work experience. Devereux (2002), for example, used a cubic in potential work experience (age minus years of schooling minus 6) and, in his analyses restricted to job stayers, a cubic in tenure with employer. Note that time-invariant individual-specific characteristics that influence wages in levels are "differenced out" in the measurement of year-to-year change.

The conventional standard error estimates accompanying ordinary least squares (OLS) estimation of equation (1) would be misleading because the error term $\varepsilon_{i t}$ is correlated across individuals in the same year. Solon, Barsky, and Parker (1994), Shin (1994), Solon, Whatley, and Stevens (1997), and Devereux (2002) therefore implemented the estimation in two steps. The first step applies OLS to the regression of $\Delta \ln w_{i t}$ on $X_{i t}$ and a vector of year dummy variables. The second step obtains estimates of $\beta$ and $\delta$ by applying least squares to the regression of the year effects estimated in the first step on $\Delta U_{t}$ 
and $t$. Unlike the earlier studies, which used OLS in the second step, Devereux used weighted least squares (WLS), weighting each year's observation by the number of individuals available for that year in the first-step estimation. The issue of optimal weighting is discussed in detail by Amemiya (1978), Dickens (1990), and Solon, Whatley, and Stevens (1997). For the sake of comparability with Devereux, we will report results based on imitating his WLS approach, but we have checked that using alternative weighting schemes leads to similar results.

Most longitudinal studies of wage cyclicality have used general samples including job changers as well as stayers and with the wage measured as "average hourly earnings," that is, the ratio of annual earnings to annual hours of work. For example, with a PSID sample of men observed from 1967-68 through 1986-87, Solon, Barsky, and Parker (1994) estimated $\beta$ at -.0140 , indicating that, when the unemployment rate rises by an additional percentage point, real wage growth tends to decline by about 1.4 percentage points. As shown in the first entry of Table 1, Devereux's corresponding estimate from PSID data for 1970-71 through 1990-91 was -.0116. ${ }^{4}$ The next entry in the first column of Table 1 shows that Devereux's $\hat{\beta}$ declined in magnitude to -.0101 when he dropped the self-employed from the sample.

The third entry shows that Devereux estimated $\beta$ at -.0081 when he restricted his sample to workers staying with the same employer from one year to the next. That estimate compares to Solon, Barsky, and Parker's (1994) estimate of -.0124 and Shin's (1994) estimate of -.0095 for young men in the National Longitudinal Surveys of labor market

\footnotetext{
4 Thanks to the remarkable thoroughness with which Devereux reported his methods, we have been able to replicate his PSID results almost exactly. Consequently, our tables comparing PSID results to NLSY results simply restate his PSID estimates instead of listing our own. The one exception is that we present our PSID results for manufacturing because Devereux did not analyze that particular sector.
} 
experience. Next, to avoid contaminating the wage measure with earnings from additional jobs, Devereux restricted his sample to stayers with no extra jobs and reestimated $\beta$ at -.0054. While tending to be somewhat smaller than the estimates from earlier studies, Devereux's initial estimates of wage procyclicality were still substantial and statistically significant.

One point of our paper is to replicate Devereux's analyses with a different data source, the NLSY. This survey began in 1979 with a national sample then between the ages of 14 and 22, reinterviewed the sample each year until 1994, and then switched to biennial interviews. In light of the NLSY's restriction to this cohort, Devereux's decision to use the PSID instead is easy to understand. On the other hand, besides affording a "second opinion," the NLSY also provides one other major advantage: because the NLSY makes a point of recording employer identifiers, it avoids the PSID's notorious difficulties with distinguishing job changers and stayers (Brown and Light, 1992). We analyze wage cyclicality among the NLSY men for the years 1979-80 through 1992-93. We stop at 1993 because, with the switch to biennial interviewing, that is the last year for which annual earnings and hours (reported for 1993 in the 1994 interview) and a directly reported hourly wage or per-period salary (reported contemporaneously in 1993) are both available. Like Devereux, we convert our nominal wage variables into real wages with the Personal Consumption Expenditure deflator. Also like Devereux, we use an "unbalanced panel" containing every year-to-year-change for which both years' observations meet our sample restrictions. In particular, we use person-years in which the person is at least 16 years old, his annual work hours are at least 300 , and both of his hourly wage measures are between $\$ 1$ and \$500 in 1987 dollars. 
The second column of Table 1 shows our NLSY-based estimates of wage cyclicality corresponding to Devereux's PSID-based estimates in the first column. Our estimates, ranging from -.0137 for the full sample to -.0113 for job stayers with no extra jobs, run somewhat higher than Devereux's and are quite similar to the estimates in earlier studies. Our estimates are subject to larger standard errors than Devereux's mainly because they are based on fewer years. Like Devereux's estimates, ours become successively smaller in magnitude as we exclude the self-employed, job changers, and stayers with extra jobs.

In the remainder of this paper, we use the NLSY and other data sources to explore Devereux's most surprising findings about stayers with no extra jobs: (1) the absence of wage cyclicality among salaried workers and (2) discrepant results between the two wage measures for workers paid by the hour.

\section{Salaried Workers}

Data limitations confined Devereux's analysis of salaried job stayers in the PSID to the narrower time period from 1976-77 through 1990-91. In addition to the average hourly earnings variable used in Table 1 and in most previous research, Devereux also used an alternative wage measure, the worker's report of his per-period salary rate in his current job. With either wage measure, Devereux found little evidence that salaried job stayers receive better raises in expansion years than in recession years. For example, as shown in the first

column of Table 2, for salaried job stayers with no extra jobs, he estimated the wage cyclicality parameter $\beta$ at only -.0008 with the average hourly earnings variable and -.0028 with the per-period salary variable. While these point estimates are small, it also is true that the associated 95 percent confidence intervals encompass quite substantial wage cyclicality (of either sign). 
We therefore considered it worthwhile to conduct a parallel analysis with another data set, the NLSY. As shown in the second column of Table 2, the NLSY data seem to tell a different story. We estimate the $\beta$ for salaried stayers with no extra jobs at -.0147 using average hourly earnings and -.0204 using per-period salary rate. Both of these estimates are more procyclical than the estimates for job stayers in the previous studies that did not separately analyze salaried workers.

To explore whether the discrepancy between the two data sets arises from the different age ranges, we have replicated Devereux's analysis with a PSID sample restricted to workers no older than 35 . The resulting estimates of $\beta$ remain very close to zero, so the difference in age does not appear to account for the discrepancy.

Like Devereux's estimates from the PSID, our estimates from the NLSY are subject to sizable standard errors. As a result, neither his estimates nor ours are very significantly different from an intermediate value like -.0080. We do not think our highly procyclical point estimates from the NLSY should be taken too literally. By the same token, we do not think that Devereux's results from the PSID should be read as proving that salaries of job stayers are noncyclical.

\section{Hourly Workers}

Devereux also analyzed wage cyclicality among workers paid by the hour. Using PSID data from 1970-71 through 1990-91, he again considered two wage variables, average hourly earnings over the calendar year and the hourly wage rate reported for the current job. As shown in the first column of Table 3, when he used the average hourly earnings variable, he obtained a significantly procyclical $\hat{\beta}$ of -.0074. In contrast, when he reestimated with the same sample but using the directly reported hourly wage rate instead, $\hat{\beta}$ was almost 
exactly zero. Swanson (1995) reported a similar finding in his PSID study that included job changers as well as stayers.

Again, we have attempted to replicate this finding in the NLSY. Our results, shown in the second column of Table 3 , are $\hat{\beta}=-.0107$ for average hourly earnings and $\hat{\beta}=-.0049$ for hourly wage rate. As in Table 1 , our estimates are more procyclical than Devereux's. Our results are consistent with his, though, in the sense that the magnitude of the discrepancy between the two wage measures is almost as large in the NLSY as in the PSID.

Devereux offered two conjectures about why this discrepancy occurs. First, he suggested that measurement error in the reporting of annual hours of work might induce a procyclical bias in the average hourly earnings variable. Second, he noted that the average hourly earnings variable is more likely to encompass pay from overtime, bonuses, tips, and so forth. As Devereux acknowledged, there was no way to corroborate either conjecture with his data from the PSID. Therefore, in the next two subsections, we explore his conjectures by referring to auxiliary evidence from the PSID Validation Study and the Bureau of Labor Statistics establishment survey.

\section{Measurement Error}

As Devereux pointed out, survey reports of earnings and work hours are notoriously susceptible to response error, and errors in reporting either earnings or work hours contribute to measurement error in the average hourly earnings variable, which is the ratio of annual earnings to annual hours. 
The usual starting point for analyzing the impact of measurement error on estimation of regression equations is the classical errors-in-variables model discussed in almost every introductory econometrics textbook. As applied here, that model is

$$
\Delta \ln E_{i t}^{*}=\Delta \ln E_{i t}+v_{E i t}
$$

and

$$
\Delta \ln h_{i t}^{*}=\Delta \ln h_{i t}+v_{h i t}
$$

where $\Delta \ln E_{i t}$ and $\Delta \ln h_{i t}$ are the true values of year-to-year growth in annual earnings and hours, $\Delta \ln E_{i t}^{*}$ and $\Delta \ln h_{i t}^{*}$ are the corresponding error-ridden measures, and $v_{E i t}$ and $v_{\text {hit }}$ are assumed to have zero mean and to be uncorrelated with the true values as well as the explanatory variables and error term in equation (1).

If we use $\Delta \ln w_{i t}=\Delta \ln E_{i t}-\Delta \ln h_{i t}$ to denote the true year-to-year growth in average hourly earnings, then the error-ridden measure is

$$
\Delta \ln w_{i t}^{*}=\Delta \ln E_{i t}^{*}-\Delta \ln h_{i t}^{*}=\Delta \ln w_{i t}+v_{E i t}-v_{h i t} .
$$

It follows that, when we estimate equation (1) with the error-ridden value of the dependent variable in place of the true one, the regression equation actually estimated is

$$
\Delta \ln w_{i t}^{*}=\beta \Delta U_{t}+\delta t+\alpha^{\prime} X_{i t}+\left(\varepsilon_{i t}+v_{E i t}-v_{h i t}\right),
$$

in which the composite error term encompasses the measurement error in the dependent variable as well as the original regression error term.

As emphasized in the standard textbook analysis, such classical measurement error in the dependent variable does not induce any inconsistency in least squares estimation of equation (5). ${ }^{5} \quad$ Least squares estimation of the regression parameters remains consistent

\footnotetext{
${ }^{5}$ This is true whether the estimation is done by single-step OLS or by the two-step method used by Devereux and ourselves.
} 
because the measurement error components of the error term are uncorrelated with the explanatory variables. Consequently, Devereux must have been assuming some sort of nonclassical measurement error when he conjectured that errors in reporting earnings or hours induce a procyclical bias in the estimation of $\beta$.

Devereux did not specify his nonclassical alternative to the textbook model, but he hinted at it when he wrote (on page 837) that "the clumping of reported hours at 40 hours per week might imply that actual hours are more procyclical than reported hours. Hence, the procyclicality of reported average hourly earnings might overstate the procyclicality of true

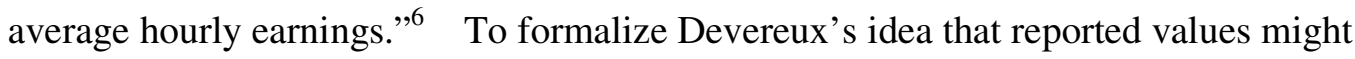
systematically understate true variation, we borrow the errors-in-variables model used in Kim and Solon (2005). That model generalizes the classical model in equations (2) and (3) to

$$
\Delta \ln E_{i t}^{*}=\lambda_{E} \Delta \ln E_{i t}+v_{E i t}
$$

and

$$
\Delta \ln h_{i t}^{*}=\lambda_{h} \Delta \ln h_{i t}+v_{h i t} .
$$

Intercepts are suppressed in equations (6) and (7) by measuring all variables as deviations from their population means. Obviously, the classical model is the special case in which $\lambda_{E}=\lambda_{h}=1$. Unlike the classical model, the generalized model allows for the possibility of systematic underreporting of true variation by permitting $\lambda$ to be less than 1 . Bound and Krueger (1991), for example, used a match of Current Population Survey responses to Social Security earnings records to estimate $\lambda_{E}$ at .65 and coined the expression "mean-reverting measurement error" to describe this departure from the classical model.

\footnotetext{
${ }^{6}$ Interestingly, Swanson (1995, page 15) made the exact opposite conjecture: "it is difficult to imagine that annual hours are misreported countercyclically - if anything, a procyclical bias seems more likely."
} 
Now we need to generalize the analysis that previously led to equation (5) to accommodate the broader assumptions of the generalized model. That leads to the generalized regression equation

$$
\Delta \ln w_{i t}^{*}=\lambda_{E}\left(\beta \Delta U_{t}+\delta t+\alpha^{\prime} X_{i t}\right)+\left(\lambda_{E}-\lambda_{h}\right) \Delta \ln h_{i t}+\left(\lambda_{E} \varepsilon_{i t}+v_{E i t}-v_{h i t}\right),
$$

which obviously specializes back to equation (5) when $\lambda_{E}=\lambda_{h}=1$. Then, one way to characterize Devereux's conjecture would be to assume that $0<\lambda_{h}<1$, representing a tendency to underreport hours variation, but that (contrary to Bound and Krueger's finding) there is no such tendency in earnings reporting, so $\lambda_{E}=1$. In that case, equation (8) would simplify to

$$
\Delta \ln w_{i t}^{*}=\beta \Delta U_{t}+\delta t+\alpha^{\prime} X_{i t}+\left(1-\lambda_{h}\right) \Delta \ln h_{i t}+\left(\varepsilon_{i t}+v_{E i t}-v_{h i t}\right) .
$$

With $0<\lambda_{h}<1$ and $\Delta \ln h_{i t}$ omitted in least squares estimation of equation (9), the standard omitted-variables analysis supports Devereux's claim that $\hat{\beta}$ would be subject to a procyclical bias.

This, however, is not a general implication of equation (8). Consider another special case, where the errors in measuring earnings and hours growth are subject to the same degree of mean-reversion, so $0<\lambda_{E}=\lambda_{h}=\lambda<1$. Then equation (8) simplifies to

$$
\Delta \ln w_{i t}^{*}=\lambda \beta \Delta U_{t}+\lambda \delta t+\lambda \alpha^{\prime} X_{i t}+\left(\lambda \varepsilon_{i t}+v_{E i t}-v_{h i t}\right) .
$$

Inspection of equation (10) makes clear that the probability limit of the estimated coefficient of $\Delta U_{t}$ would be $\lambda \beta$, not $\beta$, producing a tendency to underestimate the cyclicality of average hourly earnings.

The general point is that evaluating the nature of the inconsistency requires information on the actual values of $\lambda_{E}$ and $\lambda_{h}$. An assumption that $\lambda_{E}=1$ is contradicted by Bound and Krueger's results, but we also need information on $\lambda_{h}$. To date, 
the only data set that contains information on measurement error for changes in hours as well as earnings is the PSID Validation Study. That study, described at length in Bound et al. (1994), combined accurate information on earnings and hours from a company's records with information from a PSID-like survey of the company's workers. Bound et al.'s comparison of the survey reports of earnings and hours with the company records provided a wealth of information on properties of the measurement error in worker-reported earnings and hours. Furthermore, because the validation study was conducted in two waves four years apart, it also generated information on measurement error in changes in earnings, hours, and their ratio.

Like Bound and Krueger, Bound et al. found that the measurement error in reported earnings growth is mean-reverting. Using least squares to estimate equation (6) with a validation study sample containing both salaried and hourly workers, Bound et al. estimated $\lambda_{E}$ at .779. With twelve outliers excluded, they reestimated $\lambda_{E}$ at .782 and, when they reestimated with the full sample by least absolute deviations instead of least squares, they got $\hat{\lambda}_{E}=.853$. Their corresponding estimates of $\lambda_{h}$ for the validation study's sample of hourly workers were $.834, .862$, and $.830 .^{7}$ The general impression is that the $\lambda$ 's for earnings growth and hours growth are both about .8. If so, equation (10) is approximately applicable, and the many longitudinal studies that have found procyclical average hourly earnings may have tended to understate the procyclicality by about 20 percent.

In conclusion, the only pertinent evidence on measurement error that is currently available contradicts Devereux's conjecture that misreporting of average hourly earnings

\footnotetext{
${ }^{7}$ Based on the sample of hourly workers, Bound et al. also directly estimated the $\lambda$ for growth in average hourly earnings. Their estimates $-.671, .743$, and .790 - indicate that the net effect of the mean-reverting measurement errors in both earnings and hours growth is to understate the true variation for average hourly earnings. Kim and Solon (2005) emphasized these results in arguing that longitudinal studies of average hourly earnings have tended to understate the procyclicality of real wages.
} 
biases $\hat{\beta}$ in a procyclical direction. This leaves open the question of why directly reported hourly wages appear to be less procyclical. It is conceivable that misreporting of the growth in hourly wage rates may be subject to even more severe mean-reversion, but, to the best of our knowledge, no evidence presently exists on the nature of measurement error in hourly wage changes.

\section{Overtime Pay}

Devereux's other explanation for the discrepancy between the two wage measures was that the average hourly earnings variable is more likely to encompass pay from overtime, bonuses, tips, and the like. Swanson (1995, pages 17-18) similarly noted that "the straighttime hourly wage rates of workers are far less procyclical than their annual earnings divided by annual hours" and suggested that overtime, bonuses, tips, and commissions "play an important role" and "would be an invaluable topic for future research." Unfortunately, neither the PSID nor the NLSY provides a clear-cut disaggregation of earnings between straight-time pay and these various other components.

Nevertheless, with overtime pay as with measurement error, it is possible to learn more by combining some modeling with auxiliary evidence from another source. If we assume that all overtime work of hourly workers is paid at "time and a half," we can write a worker's average hourly earnings as

$$
w_{i t}=\left(1-S_{i t}\right) w_{b i t}+S_{i t}\left(1.5 w_{b i t}\right)=\left(1+.5 S_{i t}\right) w_{b i t}
$$

where $S_{i t}$ is the overtime share of the worker's annual work hours in year $t$ and $w_{b i t}$ denotes his straight-time or "base" hourly wage. Then, taking logarithms yields

$$
\ln w_{i t} \cong \ln w_{b i t}+.5 S_{i t},
$$

and differentiating with respect to the unemployment rate gives 


$$
\frac{\partial \ln w_{i t}}{\partial U_{t}} \cong \frac{\partial \ln w_{b i t}}{\partial U_{t}}+.5 \frac{\partial S_{i t}}{\partial U_{t}}
$$

Equation (13) confirms that the procyclicality of average hourly earnings exceeds the procyclicality of the straight-time hourly wage if the overtime share of work hours is procyclical.

It is possible to get an idea of the magnitude of $\partial S_{i t} / \partial U_{t}$ by referring to time series data from the Bureau of Labor Statistics establishment survey. Since 1956, that survey has collected information on total and overtime hours of production workers in manufacturing. The annual time series are presently available at www.bls.gov/webapps/legacy/cesbtab2.htm. Because overtime work is especially prevalent in manufacturing (Carr, 1986) and labor demand in manufacturing is especially cyclical (Mayshar and Solon, 1993; Shin, 2000), it seems likely that the magnitude of $\partial S_{i t} / \partial U_{t}$ for production workers in manufacturing sets an upper bound for the magnitude for all hourly workers.

Before estimating $\partial S_{i t} / \partial U_{t}$ for manufacturing, we should check that manufacturing exhibits the same discrepancy between the cyclicality of the two wage measures that appeared for general samples of hourly job stayers in Table 3. Table 4 repeats the analyses of Table 3 except that it focuses solely on manufacturing workers. Elsewhere in this paper, we have reported Devereux's PSID results (which we have been able to replicate almost exactly). Because Devereux did not report an analysis for manufacturing, in Table 4 we report our own PSID results for manufacturing workers as well as results from the NLSY. In both data sets, the reduced sample sizes from restricting to manufacturing impair the precision of the estimates, but, in both cases, the procyclicality estimated for average hourly earnings continues to be considerably greater than for the hourly wage rate. It is not surprising that the hourly wage is estimated to be more procyclical in the NLSY than 
in the PSID because, in some years, the NLSY questions about the current job attempted to include tips, overtime, and bonuses.

Having verified that the discrepancy between the two wage measures continues to appear for workers in manufacturing, we now proceed to using the time series data from the establishment survey to estimate the cyclicality of the overtime share for production workers in manufacturing. Concordantly with the second step of our two-step estimation of equation (1), we estimate $\partial S_{i t} / \partial U_{t}$ by applying least squares to the regression of year-to-year change in the overtime share of hours on year-to-year change in the unemployment rate and a linear time trend. The first column in Table 5 shows the results corresponding to Devereux's PSID time period, 1970-71 through 1990-91. The -.0059 estimate of the coefficient of $\Delta U_{t}$ is statistically significant and indicates that the overtime share is quite procyclical. The next column shows that, when we switch to our NLSY time period of 1979-80 through 1992-93, the estimate declines to -.0047, but remains substantial and statistically significant. Equation (13) shows that multiplying $\partial S_{i t} / \partial U_{t}$ by .5 approximates the contribution of overtime pay to the discrepancy between the cyclicalities of the two wage measures. Recalling that the overtime share probably is more procyclical in manufacturing than in most sectors, we infer from our establishment survey results that overtime might account for as much as -.003 of the discrepancy. That is a substantial quantity, but it does not account for the entirety of the large gaps reported in Tables 3 and 4 . It remains possible that still other pay besides straight-time wages, such as bonuses and tips, might explain an additional portion of the discrepancy. 


\section{Conclusions}

Our analysis of real wage cyclicality has given particular attention to Devereux's (2001) most puzzling results about job stayers. First, we have found that Devereux's estimates of noncyclical wages among salaried job stayers in the Panel Study of Income Dynamics are not replicated in the National Longitudinal Survey of Youth. Second, our NLSY analysis has replicated his PSID finding that, for workers paid by the hour, there is a discrepancy between the cyclicality of two wage measures, average hourly earnings over the calendar year and the hourly wage rate reported for the current job. Using additional evidence from the PSID Validation Study and the Bureau of Labor Statistics establishment survey, we have explored two of Devereux's proposed explanations for the discrepancy. The PSID Validation Study results contradict Devereux's conjecture that measurement error induces a procyclical bias in average hourly earnings. The BLS establishment survey evidence supports his conjecture that overtime pay contributes to the discrepancy, but it does not appear to explain all of the discrepancy.

At this stage, a fair summary of the accumulated evidence is that men's real wages are quite procyclical, with the procyclicality especially pronounced among job changers and the self-employed. Even among workers staying with the same employer, though, real average hourly earnings appear to be substantially procyclical. An important portion of that procyclicality probably is due to compensation beyond base wages, such as overtime pay and bonuses. 
Table 1. Estimated Cyclicality of Men's Real Average Hourly Earnings in Various Samples

\begin{tabular}{|l|c|c|}
\hline Sample & $\begin{array}{c}\text { Devereux's Estimates from PSID, } \\
\text { 1970-71 through 1990-91 }\end{array}$ & $\begin{array}{c}\text { Estimates from NLSY, } \\
\text { 1979-80 through 1992-93 }\end{array}$ \\
\hline Full sample & -.0116 & -.0137 \\
& $(.0021)$ & $(.0048)$ \\
& $\mathrm{N}=68,463$ & $\mathrm{~N}=45,079$ \\
\hline Minus Self-Employed & -.0101 & -.0130 \\
& $(.0021)$ & $(.0044)$ \\
& $\mathrm{N}=52,525$ & $\mathrm{~N}=42,599$ \\
\hline Minus Job Changers & -.0081 & -.0117 \\
& $(.0020)$ & $(.0035)$ \\
& $\mathrm{N}=42,164$ & $\mathrm{~N}=25,237$ \\
\hline Minus Job Stayers & -.0054 & -.0113 \\
with Extra Jobs & $(.0017)$ & $(.0025)$ \\
& $\mathrm{N}=31,957$ & $\mathrm{~N}=18,884$ \\
\hline
\end{tabular}

Numbers in parentheses are estimated standard errors. The $\mathrm{N}$ counts are the numbers of first-differenced individual-level observations in the first-stage regressions. 
Table 2. Estimated Real Wage Cyclicality for Salaried Job Stayers with No Extra Jobs

\begin{tabular}{|l|c|c|}
\hline Wage Measure & $\begin{array}{c}\text { Devereux's Estimates from PSID, } \\
\text { 1976-77 through 1990-91 } \\
(\mathrm{N}=9,078)\end{array}$ & $\begin{array}{c}\text { Estimates from NLSY, } \\
\text { 1979-80 through 1992-93 } \\
(\mathrm{N}=7,745)\end{array}$ \\
\hline Average Hourly & -.0008 & -.0147 \\
Earnings & $(.0039)$ & $(.0066)$ \\
\hline Per-Period Salary Rate & -.0028 & -.0204 \\
& $(.0067)$ & $(.0061)$ \\
\hline
\end{tabular}

Numbers in parentheses beneath coefficient estimates are estimated standard errors. The $\mathrm{N}$ counts are the numbers of first-differenced individual-level observations in the first-stage regressions. 
Table 3. Estimated Real Wage Cyclicality for Hourly Job Stayers with No Extra Jobs

\begin{tabular}{|l|c|c|}
\hline Wage Measure & $\begin{array}{c}\text { Devereux's Estimates from PSID, } \\
\text { 1970-71 through 1990-91 } \\
(\mathrm{N}=15,544)\end{array}$ & $\begin{array}{c}\text { Estimates from NLSY, } \\
\text { 1979-80 through 1992-93 } \\
(\mathrm{N}=4,838)\end{array}$ \\
\hline Average Hourly & -.0074 & -.0107 \\
Earnings & $(.0022)$ & $(.0052)$ \\
\hline Hourly Wage Rate & -.0001 & -.0049 \\
& $(.0020)$ & $(.0047)$ \\
\hline
\end{tabular}

Numbers in parentheses beneath coefficient estimates are estimated standard errors. The $\mathrm{N}$ counts are the numbers of first-differenced individual-level observations in the first-stage regressions. 
Table 4. Estimated Real Wage Cyclicality in Manufacturing for Hourly Job Stayers with No Extra Jobs

\begin{tabular}{|l|c|c|}
\hline Wage Measure & $\begin{array}{c}\text { Estimates from PSID, } \\
\text { 1970-71 through 1990-91 } \\
(\mathrm{N}=6,237)\end{array}$ & $\begin{array}{c}\text { Estimates from NLSY, } \\
1979-80 \text { through 1992-93 } \\
(\mathrm{N}=1,427)\end{array}$ \\
\hline Average Hourly & -.0131 & -.0100 \\
Earnings & $(.0036)$ & $(.0045)$ \\
\hline Hourly Wage Rate & -.0010 & -.0045 \\
& $(.0032)$ & $(.0081)$ \\
\hline
\end{tabular}

Numbers in parentheses beneath coefficient estimates are estimated standard errors. The $\mathrm{N}$ counts are the numbers of first-differenced individual-level observations in the first-stage regressions. 
Table 5. Estimated Cyclicality of the Overtime Share of Hours for Production Workers in Manufacturing

\begin{tabular}{|l|c|c|}
\hline & $\begin{array}{c}\text { 1970-71 through 1990-91 } \\
\text { (PSID Sample Period) }\end{array}$ & $\begin{array}{c}\text { 1979-80 through 1992-93 } \\
\text { (NLSY Sample Period) }\end{array}$ \\
\hline Estimate of $\partial S / \partial U$ & -.0059 & -.0047 \\
$(.0012)$ & $.0015)$ \\
\hline$R^{2}$ & .56 & .49 \\
\hline $\begin{array}{l}\text { Durbin-Watson } \\
\text { Statistic }\end{array}$ & 1.76 & 2.08 \\
\hline
\end{tabular}

Numbers in parentheses beneath coefficient estimates are estimated standard errors. 


\section{References}

Amemiya, Takeshi. 1978. “A Note on a Random Coefficients Model.” International Economic Review, Vol. 19, No. 3 (October), pp. 793-96.

Bils, Mark J. 1985. "Real Wages over the Business Cycle: Evidence from Panel Data." Journal of Political Economy, Vol. 93, No. 4 (August), pp. 666-89.

Blanchard, Olivier Jean, and Stanley Fischer. 1989. Lectures on Macroeconomics. Cambridge, Mass.: MIT Press.

Bound, John, Charles Brown, Greg J. Duncan, and Willard L. Rodgers. $1994 . \quad$ "Evidence on the Validity of Cross-sectional and Longitudinal Labor Market Data.” Journal of Labor Economics, Vol. 12, No. 3 (July), pp. 345-68.

Bound, John, and Alan B. Krueger. 1991. "The Extent of Measurement Error in Longitudinal Earnings Data: Do Two Wrongs Make a Right?” Journal of Labor Economics, Vol. 9, No. 1 (January), pp. 1-24.

Bowlus, Audra J. 1993. "Job Match Quality over the Business Cycle.” In H. Bunzel, P. Jensen, and N. Westergard-Neilsen, eds., Panel Data and Labor Market Dynamics. Amsterdam: North Holland, pp. 21-44.

Brown, James N., and Audrey Light. 1992. "Interpreting Panel Data on Job Tenure." Journal of Labor Economics, Vol. 10, No. 3 (July), pp. 219-57.

Carr, Darrell E. 1986. “Overtime Work: An Expanded View.” Monthly Labor Review, Vol. 109, No. 11 (November), pp. 36-39.

Devereux, Paul J. 2001. “The Cyclicality of Real Wages within Employer-Employee Matches." Industrial and Labor Relations Review, Vol. 54, No. 4 (July), pp. 835-50.

Dickens, William T. 1990. "Error Components in Grouped Data: Is It Ever Worth Weighting?" Review of Economics and Statistics, Vol. 72, No. 2 (May), pp. 32833.

Kim, Bonggeun, and Gary Solon. 2005. "Implications of Mean-Reverting Measurement Error for Longitudinal Studies of Wages and Employment.” Review of Economics and Statistics, Vol. 87, No. 1 (February), pp. 193-96. 
Mayshar, Joram, and Gary Solon. 1993. " "Shift Work and the Business Cycle." American Economic Review, Vol. 83, No. 2 (May), pp. 224-28.

Shin, Donggyun. 1994. "Cyclicality of Real Wages among Young Men.” Economics Letters, Vol. 46, No. 2 (October), pp. 137-42.

Shin, Donggyun. 2000. "Gender and Industry Differences in Employment Cyclicality: Evidence over the Postwar Period.” Economic Inquiry, Vol. 38, No. 4 (October), pp. 641-50.

Shin, Donggyun, and Kwanho Shin. 2002. "Why Are the Wages of Job Stayers Procyclical?" Unpublished paper, Hanyang University.

Solon, Gary, and Robert Barsky. 1989. "Real Wages over the Business Cycle." Working Paper No. 2888, National Bureau of Economic Research.

Solon, Gary, Robert Barsky, and Jonathan A. Parker. 1992. " "Measuring the Cyclicality of Real Wages: How Important Is Composition Bias?” Working Paper No. 4202, National Bureau of Economic Research.

Solon, Gary, Robert Barsky, and Jonathan A. Parker. 1994. "Measuring the Cyclicality of Real Wages: How Important Is Composition Bias?” Quarterly Journal of Economics, Vol. 109, No. 1 (February), pp. 1-25.

Solon, Gary, Warren Whatley, and Ann Huff Stevens. 1997. "Wage Changes and Intrafirm Job Mobility over the Business Cycle: Two Case Studies.” Industrial and Labor Relations Review, Vol. 50, No. 3 (April), pp. 402-15.

Swanson, Eric. 1995. " "Real Wage Cyclicality in the PSID, 1967-1991.” Unpublished paper, Federal Reserve Board of Governors. 